\title{
7. Cost-benefit analysis: a tool that is both useful and influential?
}

\section{Giles Atkinson ${ }^{1}$}

\section{INTRODUCTION}

The recommendation that policymakers should go ahead with public policies and projects only if the benefits of these proposals outweigh the costs has a common-sensical appeal. Articulating this intuition more rigorously in policy formulation is the domain of cost-benefit analysis (CBA), or variants which draw on the same conceptual framework. There is an extensive academic literature on CBA, some of which may not use the term 'cost-benefit analysis' but instead refers to 'benefit-cost analysis', 'policy evaluation' or 'project appraisal'. Numerous texts and manuals have appeared covering CBA generally (for example, Boardman et al. 2011), in developing countries (for example, Londero 2003) and applications such as environment (Hanley and Barbier 2009; Pearce et al. 2006). A number of characteristics make CBA distinctive as a policy formulation tool. Perhaps most notably, it is an attempt to quantify costs and benefits in monetary terms. This, in turn, relies on an assessment of how people whose wellbeing is affected by policy actions value those losses and gains.

But while economic texts give every impression that CBA has all the answers, in practice there is some recognition that CBA is only one input to policy formulation decisions. The very act of carrying out a CBA presupposes, for example, that physical impacts have been understood sufficiently to bring them into the ambit of an economic appraisal. In addition, CBA sits side-by-side with a number of assessment tools and metrics all purporting, in different ways, to indicate the worth of a policy action. Moreover, none of these mechanical tools (including CBA) is a substitute for human judgement. The decision process here might be conceived of as policymakers having all this multidimensional information at their disposal and using it to inform a rational (or at least a sensible) choice that represents an overall improvement for society.

That, at least, might be the notion in principle. So while this chapter begins by setting out what makes CBA distinctive and how it is intended 
to be used, in what follows, the main purpose is to consider how CBA operates in the 'real world': the actual world of policy formulation beyond the textbook. This discussion reviews evidence regarding two related but distinct concerns: whether CBA is actually used in policy formulation and whether it is influential in this process (perhaps in the sense of what policy outputs and outcomes are actually adopted). Published evidence is somewhat sparse, especially in the latter dimension. However, what seems clear is that policymakers cannot simply be assumed always to be choosing actions so as to achieve societal improvements as CBA practitioners might like to assume. In these respects, CBA might be downgraded or given less prominence than other (non-CBA) evidence used in informing decisions. Understanding what these decision makers actually do is critical too from the perspective of making sense both of how the policy formulation process actually works and how guidance, which might enhance this process, can be more influential in future.

\section{WHAT IS COST-BENEFIT ANALYSIS?}

The conceptual case for thinking about costs and benefits in formulating policy is typically cast in the relatively narrow terms of welfare economics. In practical terms, this places an emphasis on the efficiency with which, for example, public funds are spent. This conceptual foundation offers considerable strength, built as it is on an intellectual tradition which dates back many decades (see, for the history of CBA, Pearce 1998 and Persky 2001). It confers a weakness too: well-known problems identified, in theory, with these welfare economic foundations also become a problem for the practical application of CBA (see Gowdy (2004) as an exemplary critique in this vein).

A broader rationale for CBA, however, is put forward by Randall (2002). There are many reasons, he argues, why a policy action can be viewed as a good thing (or otherwise). But broadly speaking, two such reasons relate to the 'rightness' of the action and its consequences. In this respect, CBA 'exists' to say something more tangible about the former. That is, the likely benefits and costs of actions can be viewed as one important input needed to make sensible decisions about whether policy proposals are good or otherwise. Put this way, CBA is not just the transfer of cold market logic to all policy venues, which can then simply be rejected if one chooses to reject the underlying premise for this transfer. Instead, costs and benefits are something that 'benign and conscientious' policymakers should be interested in more generally if they are concerned with creating good consequences as a result of their decisions (Randall 2007, p.92). 
From this starting point, CBA can be interpreted as constructing an elaborate policy formulation tool that enables the quantification of these costs and benefits to the fullest extent possible. Stokey and Zeckhauser (1978, p. 134) define it as:

the principal analytical framework used to evaluate public expenditure decisions. The approach requires systematic counting of all costs and benefits, tangible and intangible, whether readily quantifiable or difficult to measure, that will accrue to all members of society if a particular project is adopted.

According to this quotation, the scope of CBA is truly vast, the ambition level is high and the ensuing economic evaluation apparently trumps all else in informing any decision. For example, it is not circumscribed by looking at the worth of an action from the standpoint of any particular stakeholder or interest group. Instead CBA works on the basis that any gain or loss to anyone who has standing (in other words, who counts) must be included. Nor is the approach, in principle, restricted to any particular policy venue. We discuss what this might mean in practice in the section below.

\section{What is Distinctive about Cost-Benefit Analysis as a Policy Formulation Tool?}

While the practical details can vary, the basic structure of any cost-benefit analysis takes the same form the world over. It involves summing the monetary value of net benefits (benefits minus costs) over the lifetime of a project or a policy. For a typical intervention, there will be costs now in return for benefits later. This leads to a crucial point: this stream of net benefits is discounted. What this means is that the value of net benefits in each period are not just added together but are treated differently depending on when they occur in time. Specifically, less and less weight is given to costs or benefits the further these impacts are in the future. These discounted net benefits are summed to estimate the net present value (NPV) of the project or policy. The decision rule in CBA is to recommend that the action goes ahead if the sum of (discounted) net benefits is greater than zero: that is, NPV $>0$. If we are choosing between mutually exclusive projects, then a CBA would recommend the project with the greatest net benefits.

The emphasis of conventional CBA is on securing overall net gains rather than their distribution. Placing this spotlight on total costs and total benefits does not necessarily reflect a judgement that distributional concerns 'do not matter'. Rather it assumes that the issue of who gains and who loses can be dealt with separately to the issue of making decisions, so as to generate as much overall 'goodness' of action as possible. ${ }^{2}$ 
Nevertheless, there are well-known procedures in CBA to deal with the benefits received and costs incurred by different societal groups. Indeed, in the UK, official guidance on CBA clearly states that:

Any distributional effects identified should be explicitly stated and quantified as far as possible. At a minimum, this requires appraisers to identify how the costs and benefits accrue to different groups in society .... Where it is considered necessary and practical, this might involve explicitly recognising distributional effects within a project's NPV. (HM Treasury 2003, p.91)

Yet it is rare for such advice to be followed to the letter. Some deviation is understandable. What distributional weights should be applied is a matter of significant debate and uncertainty. Cost-benefit analysts can be forgiven perhaps for steering clear of these deep waters. However, it is harder to justify why relatively simple steps - such as identifying and cataloguing how costs and benefits are distributed - are seldom seen.

Another distributional dilemma surrounds discounting which, on the face of it, appears inconsistent with the spirit of 'intergenerational equity'. The reason is that the higher the discount rate used the more likely it is that (other things being equal) decisions are shifted towards actions which bring more immediate net benefits. Moreover, impacts occurring relatively far into the future receive almost no weight for any positive discount rate. Not surprisingly then, the choice of discount rate for policies with long-term consequences is especially controversial. For example, in the case of assessing the economic burden of climate change, this debate has highlighted fundamental differences between those economists who see a role for the practitioner to make, or reflect, explicit moral judgements about intergenerational equity and those who argue for a more objective approach based on information revealed in actual economic decisions about how much people care about the future (IPCC 1996; Stern 2007; Weitzman 2007). Resolving such debates is far from straightforward and faces profound questions on which, to quote Beckerman and Hepburn (2007, p. 198), 'reasonable minds may differ'. While it is important, therefore, that cost-benefit appraisal codifies and accommodates these differences, this may incur a penalty in the sense of less decisive recommendations.

Current interest in CBA stems from a variety of motivations. In part, however, the growing ability of practitioners to place robust money values on intangible impacts has surely played a crucial role. In environmental applications of CBA, for example, the estimation of these non-market values has given rise to a proliferation of methods. ${ }^{3}$ Some involve estimating original values by looking at actual behaviour. An example here would be the costs that visitors incur (in terms of out-of-pocket expenses 
and time costs of visits) to participate in nature-based recreation. Other methods elicit values by looking at intended behaviour. These stated preference methods involve people being asked more directly about the value they place on a policy change (see, for example, Alberini and Kahn 2006). Critical scrutiny of such techniques has also been prominent however. Grounds for criticism vary. For some, all non-market valuation appears to be controversial. Others make a distinction between certain classes of (non-market) goods which morally should be beyond valuation (for example, Kelman 2005), or technically defy robust valuation given the state-of-the-art in valuation practice (for example, Bateman et al. 2008; 2010). None of this criticism is necessarily a bad thing. A healthy dose of scepticism is important in the application, use and interpretation of any empirical methodology and non-market valuation is no exception.

\section{Policy Venues and Cost-Benefit Analysis}

The policy venues in which CBA might be used and, in turn, influence policy formulation can be viewed from a number of perspectives. First, there is use according to (the scale of a) particular intervention. While such interventions are typically conceived as discrete projects, these can be relatively large or relatively small. Quite often there is a cost threshold above which the need for a CBA is triggered (see, for example, European Commission, (2008), in the context of the EU). Indeed, some of these projects might have economic and social consequences across a significant geographical area and population (for example, in the UK, the proposals for a high-speed rail network). In many instances, the 'project' might be better construed as a (change in) policy (for example, the introduction of the London Congestion Charge) or even an entire strategy (which may itself imply that a range of policies are initiated or reformed). The use of CBA in the UK's air quality management strategy would be one example of the latter (see Defra 2007). It is also worth noting that CBA has been used for an agenda-setting role too. In the UK, the Stern Review on the Economics of Climate Change (Stern 2007) and the National Ecosystems Assessment (NEA 2011) are prominent examples of this.

Second, there is use as classified by tier of government or institution. In the UK, national government (or those performing appraisals on its behalf) is arguably the principal user of CBA. There is less (if any) evidence of use amongst local government authorities. However, in the environmental sector, a range of public bodies also employ this approach, including the Environment Agency as well as other regulatory agencies such as OfGEM (the Office of Gas and Electricity Markets) for the electricity sector, and OfWAT (the Water Services Regulation Authority) for the water sector. 
Moreover, social CBA is also used in the private sector. Companies in the water industry in England and Wales, for example, must use social CBA as one element of the investment case that they put forward to OfWAT under the periodic pricing reviews that the sector is subject to.

Third, there is use of CBA by characteristic of the policy sector, be this transport, environment or criminal justice for example. In the UK, impact assessment obligations provide the institutional impetus behind CBA (see Chapter 9, this volume), a feature shared by many countries. Perhaps unsurprisingly it is the policy department in the UK that is most associated with economic policy - HM Treasury - that is both custodian of how CBA is done and responsible for extending its use across government. Focal to this is the detailed guidance on how to value costs and benefits in monetary terms in what is popularly known as the Greenbook (HM Treasury 2003). In effect, such guidelines are the bridge between the CBA textbook world and the real world of practical implementation. Some organizations develop this guidance further. The Department for Transport's WebTAG (its online Transport Appraisal Guidelines: www.dft.gov.uk/webtag/) is the UK exemplar here. Dunn (2012) provides detailed guidance on nonmarket valuation of environmental impacts which has the status of supplementary Greenbook guidance. What this more specific guidance reflects is not only the increasing use of CBA in environmental policy but also the growing need for 'non-environment' ministries nevertheless to appraise the environmental impacts of their own proposals. For some policy departments, the application of CBA is less firmly established. Criminal justice and policing is one broad example here. However, this does not mean that economic approaches are absent altogether from policy thinking, as illustrated by the publication of figures estimating the UK costs of crime (Dubourg and Hamed 2005).

Other countries also have their own specific CBA guidance (see Chapter 9, this volume) although general principles will be broadly similar. For example, in the environmental policy context in the USA, CBA is widely used and the Environmental Protection Agency (EPA) has its own extensive guidelines (US EPA 2000) for preparing economic analyses of regulations. In many of these cases, the driving force for the use of CBA still comes from central government. Important centres of guidance have come from other institutions too. The European Commission is committed to applying some form of cost-benefit test to its directives. CBA has been used in guiding decisions about disbursing the EU's Structural and Cohesion Funds which, over the period 2007-2013, amounted to more than $€ 300$ billion. How best to spend this money is thus a very real challenge although the high-level objectives are plain enough: the assistance of socially and economically disadvantaged areas of the EU through the 
financing of projects which are net beneficial on the basis of a cost-benefit assessment. How parties applying to the EU's Structural and Cohesion Funds (SCF) should carry out this CBA is illustrated in a guidance document (European Commission 2008). The World Bank also has its own formal (practice) guidelines entitled Operational Policy on the Economic Evaluation of Investment Operations (Belli et al. 1998).

\section{Cost-Benefit Analysis and Other Decision Making Procedures}

CBA examines the social justification for a policy proposal. It is thus distinct from a financial assessment which looks only at the bottom-line for the implementing agency. In many instances, however, economic appraisal will consist of both social CBA and the financial case. For example, when a regional authority applies for financial support - under the SCF - to invest in its conventional rail network or a water treatment plant, it will do so first by demonstrating that the relevant project has a social NPV that is positive. However, the EU is also concerned about evidence regarding the financial case for the project. If the financial net benefits are greater than zero then the project will not be financed by the EU. Put another way, this project pays its own way and is judged not to need external financing under the SCF. Put another way, funding is only approved if the project has a social CBA justification but is not financially viable for the authority making the application.

In some circumstances, the monetary value of impacts might be highly uncertain or defy sensible calculation altogether. In such cases, cost effectiveness analysis (CEA) could be used to ascertain the cost at which a proposal is able to secure a unit of some specified benefit. In its simplest form, there is a single indicator of effectiveness, $E$, which is compared with a cost of $C$. The usual procedure is to produce a cost-effectiveness ratio (CER): $C E R=E / C$. For example, this ratio might be read as $£$ per life saved. From this perspective, multi-criteria analysis (MCA), discussed in Chapter 6, is similar to CEA but involves multiple indicators of effectiveness.

A key distinction between CBA and both CEA and MCA is that while all offer guidance on which of several alternative policies (or projects) to select, the latter two approaches are silent on whether or not it is worth adopting any policy action at all. The notion of 'worth doing' only has meaning if costs and benefits can be compared in a manner that enables a judgement to be made about whether costs are greater (or smaller) than benefits. And this, in turn, requires that costs and benefits have a common numeraire which in CBA is money. Nor is it clear how MCA deals with issues of time. How time is treated in CBA is sometimes controversial. But it is at least explicit, whereas in MCA it is implicit. More positively, 
distributional implications are usually chosen as one of the objectives in an MCA and hence equity concerns can be clearly accommodated. All of this adds to the impression that MCA and CBA are complements rather than substitutes.

Even where costs and benefits can be valued, ${ }^{4}$ these impacts may have complex pathways. Tracing and quantifying such impacts over the economic life of the project or policy is the necessary precursor to valuing them. Environmental applications of CBA provide perhaps the best illustration here. Measuring physical impacts needs to be based on a sound body of natural science. For example, in the case of evaluating air quality management proposals, this requires an understanding of how air pollutants (reduced from some emission source) otherwise would have been dispersed. This is important because the chief benefit of these proposals is likely to be improved health enjoyed by people currently exposed to reduced pollution. Assessment of these changes in health states (reduced mortality or reduced morbidity) requires an understanding of the epidemiology of exposure and health impact. Only after all this is estimated can the resulting impacts be valued in money terms.

This creates an obvious linkage of CBA to those assessment techniques which seek to quantify physical impacts of policy actions. Environmental Impact Assessment (EIA) is one example. EIA can be thought of as a procedural venue that hosts a number of different appraisal tools. However, it is also the point at which basic information about the physical consequences for the environment of a proposal are measured and collected. In this way, EIA is also an essential input to CBA. CBA covers the other impacts of projects and policies, and goes one stage further than EIA by attempting to put money values on the environmental impacts. Unlike CBA, EIA has no formal decision rule attached to it: for example that benefits must exceed costs. However, analysts would typically argue that its purpose is to look at alternative means of minimizing the environmental impacts without altering the benefits of the project or policy. Whatever the case, EIA and CBA are not substitutes for one another.

Strategic environmental assessment (SEA) provides a further possibly complementary role. Instead of single projects or policies, SEA considers broader programmes of investments or policies. The goal is to look for the synergies between individual policies and projects and to evaluate alternatives in a more comprehensive manner. The emphasis on strategic is important. A weakness of the cost-benefit approach is that, in practice, it does tend to deal with decisions incrementally and in isolation.

An example is the evaluation of impacts on the natural environment that a transport infrastructure project might have. It is important to see the changes in landscape and ecology that might occur here not just in 
terms of the specific location affected by this specific project but also in terms of the cumulative effect of past decisions (as well as potential future decisions). This strategic view is highly useful if the policy concern is that (some aspect of) the natural environment is maintained overall. What this does is make a principle of 'ecological sustainability' applicable to the portfolio of policy actions. A strategic view, in this respect, would be essential for assessing whether this constraint is being observed.

\section{HOW AND WHERE DOES CBA WORK IN THE REAL WORLD?}

The existence of official procedures for undertaking CBA for policy formulation, discussed above, provides a prominent and focal indicator of potential use of economic appraisal. However, the existence of such procedures cannot be taken as an indication that CBA is actually used or that it is influential. To make such claims, further evidence about actual practice must be sought (Hahn and Dudley 2007; Hahn and Tetlock 2008). 'Use', for example, might be equated to actual uptake - that is, its presence in an impact assessment - although this should also involve asking questions about how comprehensive these uses were as well as their quality. Assessing 'influence' on policy outputs and ultimately outcomes is arguably more difficult still, requiring further quantitative and qualitative investigation. In what follows, we comment on a selection of the evidence that appears to throw light on some of these issues.

\section{The Use and Quality of CBA}

One sobering reflection on the use of CBA in the World Bank was revealed in a recent assessment by the Independent Evaluation Group (IEG 2011). The most striking headline was that the requirement for CBA formally codified in the Bank's operational procedures (OP10.04) was followed far less in practice (see also Little and Mirrlees 1994). The proportion of World Bank projects using CBA dropped significantly from 1970 to 2000. According to the Independent Evaluation Group (IEG 2011), one (proximate) explanation for this trend was a shift in investment portfolio from policy sectors with a tradition of using CBA (for example, energy, transport and urban development) to those which do not (for example, education, environment and health). Nonetheless, the group's report still found a significant reduction in the use of CBA in traditional sectors in which the World Bank remains heavily committed in terms of its investments (for example, physical infrastructure). Moreover, given the strides made in 
extending CBA thinking and practice to novel project venues, a question inevitably arises as to why this progress has not been translated into actual appraisal in these new sectors.

How generalizable are such findings? While not straightforward to judge systematically, an earlier report by OECD (2004) states that despite the desirability of CBA, it is not used in many of its member countries because of the difficulties of placing money values on a comprehensive range of costs and benefits. In the US, a review of 74 impact assessments issued by the US EPA from 1982 to 1999 found that while all of the policy actions contained in these assessments monetized at least some costs, only about half monetized some benefits (Hahn and Dudley 2007). Fewer still (about a quarter on average), provided a full monetized range of estimates of benefits, although the number doing so increased notably over the sample period. This raises important points. Clearly, there is more to do to increase the use of CBA, not least to bring actual practice in line with official guidelines. However, it is not the case that use of economic appraisal is entirely lacking; it is usually present but often partial.

A logical further question is whether, when applied, CBA applications were any good in the sense of conforming to good practice, following official guidance that an institution itself has adopted or being judged as good quality according to some recognized criteria. Some of the indicators assembled by Hahn and Dudley (2007) for the US identify a number of relevant issues. For example, even for those (US EPA) applications which estimated costs and/or benefits, it was relatively uncommon for these estimates to be complete (rather than monetizing a small subset of impacts) and for point estimates to be accompanied by a range (that is, low and high estimates of the value of a given impact). Moreover, the consideration of different options or alternatives, in cost-benefit terms, was also infrequent. More commonly, practice involved simply comparing some (presumably) favoured single option for a policy change with the status quo. A similar finding emerged from another recent study of EU studies of environmental projects for which financing was requested under regional assistance schemes (COWI 2011).

Another way in which quality might be assessed is by asking how accurate $\mathrm{CBA}$ is in what it attempts to measure. Testing this might involve a mechanical exercise to compare the results of ex ante and ex post CBA studies of the same intervention. An ex ante CBA is essentially a forecast of the future: estimating likely net benefits in order to inform a decision to be made. Ex post CBA - that is, conducting further analysis of costs and benefits of an intervention at a later stage - can be viewed therefore as a 'test' of that forecast. In other words, what can we learn - for example, for 
future, similar applications or regarding the accuracy with which CBA is undertaken generally - with the benefit of this hindsight?

Flyvbjerg et al. (2003) provide a meta-study of the ex ante and ex post costs of transport infrastructure investment in Europe, USA and other countries (from the 1920s to the 1990s). The results are revealing: ex post cost escalation affected 90 per cent of the projects they examined. Nor are cost escalations a thing of the past according to these data. This illustrates one aspect of a broader problem afflicting real world CBA of 'appraisal optimism': offering ex ante estimates of costs that are lower than they turn out to be in reality. In reaction to this, HM Treasury (2003) states that capital costs estimates for UK public appraisal of physical infrastructure investments should be increased in any CBA by about two-thirds. This direction of bias is evident for projects which involve large investment in physical infrastructure. The opposite can be found in the case of policy regulations. For example, MacLeod et al. (2009) find evidence across the EU for lower regulatory costs ex post than predicted ex ante, a finding they attribute to firms affected by these burdens finding more costeffective ways of complying with policy. For the US, however, Hahn and Tetlock (2008) find no systematic evidence of such bias.

\section{The Influence of CBA}

The fact that the quality of many CBA applications falls short - and possibly far short - of what is specified in textbooks and official guidelines might lead to scepticism about whether politicians are seriously committed to using economic appraisal to guide policy formulation. It may even be the case that CBA is seen simply as a box to tick, perhaps because it is an obligation (COWI 2011). While it would be a mistake to claim that CBA has no influence at all, it would be equally erroneous to claim it is nearly always influential.

Yet, determining the extent of influence is far from straightforward. For example, IEG (2011) find relatively higher returns for World Bank projects for which ex ante CBA had been undertaken. Yet, disentangling the influence of appraisal from other confounding factors is a challenge. Hahn and Tetlock (2008) review evidence of influence of economic appraisal on a number of health and safety regulations in the US. This appears to indicate little effect in weeding out regulations which protect life and limb at inexplicably high cost. Moreover, where influence can be identified it tends to be on formulating the details of a specific proposal rather than using this same economic thinking to inform more broadly what the options are.

The fact that decisions are often inconsistent with, or downplay, CBA 
can be squared with the reality that, in practice, CBA is only one input to the decision and, in some circumstances, other considerations trump economic thinking (see Chapter 9, this volume). The experience of the London Congestion Charge illustrates how economic considerations are balanced in this way. The scheme requires that those motorists entering the congestion charge zone around central London during designated hours must pay a charge. The cost-benefit case for a charge in London was arguably long-standing (Newbery 2006). However, the (initial) £5 daily charge appears to have been largely politically determined. That is, it was not an amount which would provide Londoners with the maximum net benefits (Santos and Fraser 2006). Even so, the official CBA which accompanied the proposal for the congestion charge showed that it would create benefits in excess of costs. In addition, distributional concerns shaped the formulation of the charge: certain groups are exempted or face a lower charge. Such provisions plausibly entail some sacrifice in the cost-benefit gain. Presumably decision makers surmised that this sacrifice was justified if it helped allay public perceptions about the acceptability of the charge.

In other cases, it may be that decision makers have taken an extreme stance on some of the criticisms of CBA: whether it is sufficiently deliberative in the sense of ensuring groups have some sway over decision making (in addition to having their costs and benefits counted in a CBA) (Turner 2007) or whether estimates of costs and benefits are sufficiently robust to base serious decisions on. The evaluation of London's 'Supersewer' perhaps provides an example of this. This project is a major physical investment in London's sewage system proposed by Thames Water plc, which would be financed by higher water charges for customers. The benefits of this are largely intangible, stemming from a substantial decrease in the wastewater discharges into the River Thames that occur currently. The assessment of this proposal involved two cost-benefit studies. The first found a case on economic grounds by looking only at the costs and benefits to households in the Thames Water region (for example, see Mourato et al. 2005). Even so, the project was rejected by the water sector regulator apparently because of a mix of concerns about the reliability of benefit estimates, the way in which higher water bills might impact on poorer households as well as whether different investment options had been adequately considered.

A second CBA study (of the same project) was undertaken a few years later. Notably, this re-valued the intangible benefits on the basis of new ecological data as well as looking at benefits to people beyond the Thames region (given the cultural significance of the River Thames). While this second study found the cost-benefit case lacking if only Thames Water 
customers were considered, if benefits to people living beyond that area were included, the project was justified. This time around the project gained the necessary political support and was approved. What circumstances changed between these two studies is a matter of speculation. However, it would be difficult to sustain the argument that the primary reason was that the second CBA was simply better and more credible (although, to confound matters, it possibly was). More generally, while there is genuine complexity in undertaking a full CBA, it is probably more likely that such concerns often provide a flag of convenience behind which other (more political) motives might hide.

In the case of London's bid to host the 2012 Summer Olympic Games, the decision to bid was essentially political (although presumably sporting criteria also played some part) and economic analysis largely an afterthought. Yet, the cost of London 2012 was comparable with many large infrastructure investments (and indeed was probably more than twice the likely cost of the London Supersewer project). Indeed, the evident costs of London 2012 did necessitate some search for evidence; but with the political onus to prove that the Games must surely be value for money. Interestingly, nowhere in this defence was there any consideration of the economic assessment of benefits that had been undertaken by the organizations responsible for the bid (see Atkinson et al. 2008 and Blake 2005). There was also an equally pressing wish to show that the benefits would be evenly distributed across the UK. This was important because the costs of paying for the Games are likely to be evenly spread across UK taxpayers.

The case of London 2012 is somewhat exceptional as a policy venue. Yet the way in which economic assessment has (and has not) influenced policy formulation in a venue with a more deep-rooted tradition of using CBA is just as interesting. The HS2 project is a proposed transport investment linking London with the Midlands and North of England by high speed rail. CBA formed part of the official case for the government's financial support for this wholly new rail infrastructure and purchase of required new rolling stock. This economic case, it appears, is fairly marginal: a finding to put in the context of the general ex post experience elsewhere of lower benefits and/or higher costs than anticipated ex ante (de Rus and Nash 2007). There has been significant scrutiny of the official CBA of HS2, not just restricted to the likely rising financial cost of the project. Discussion has also focused on costs which were left out; particularly the landscape changes and biodiversity losses that the new infrastructure may cause. Debate has also surrounded the estimation of time savings for business travellers that a faster train service provides. What is interesting here is the way in which cost-benefit arguments have contributed to shaping this debate and that, moreover, the economic content of this debate has 
not been the sole preserve of technical experts. Whether this is genuine influence or whether - given CBA's prominence in the venue of transport policy - this is the way that arguments 'must' be couched to be heard is another matter.

As Hahn and Tetlock (2008) note, policy decisions are by their very nature political. It is probably also the case that this is more overt in some policy venues than others. Discussions about the influence of CBA clearly need to consider its 'political economy' (see Chapter 9, this volume). That is, rather than merely choosing what is best for social wellbeing as assumed in CBA textbooks, governments and their constituent decision makers are faced with political realities that necessitate the reconciliation of conflicting, or satisfying of particular, interests. Favouring CBA might not be the best way of serving those ends (Pearce et al. 2006). In this sense, decisions which have already been made - and the need to justify those decisions - end up constraining the analysis and the evidence (IEG 2011). Undertaking a thorough CBA from the outset of the policy formulation process might strike decision makers as politically risky. Put another way, CBA might provide a different answer to the one that a policymaker wants; something that David Pearce (1998) refers to as CBA removing flexibility in politics.

Another way in which these political economy considerations might be important is in explaining, in part, apparently technical phenomena such as appraisal optimism. This has been explored by Florio and Sartori (2010) in the context of the EU appraisal of the Structural and Cohesion Funds discussed earlier. The problem here arises because in making its decision to approve financing for projects, the EU is reliant on the information (about costs and benefits) that it receives from those in eligible regions proposing the action. This might be a regional or national authority which in turn could be using information provided by private agents (for example, a contractor of some description). COWI (2011, p. 13) illustrates the incentive problem starkly here in the following quotation from a Member State representation, suggesting that appraisal is: 'a matter of making the financial analysis look as bad as possible in order to increase the funding need, and to make the economic analysis to look as positive as possible in order to justify the public funding'. There is an increasing suspicion that such incentives could explain a lot of what were previously thought to be simply technical-analytical shortcomings. De Rus (2011) is particularly concerned about rail projects: demand forecasts always seem too high and cost forecasts always seem to be too low, viewed from an $e x$ post perspective. Forecasting is undoubtedly challenging and so may result in technical errors being made. However, strategy possibly plays its part as well. 


\section{DISCUSSION AND CONCLUSIONS}

Cost-benefit analysis has been developed over a long period of time and most of its advocates would argue that even if policies are not solely formulated on the basis of CBA, decisions at least should be informed by it. Thus, CBA is a normative policy formulation tool for making recommendations to policymakers about what they should do. However, there is a greater role than currently obtains for positive analysis of when and why CBA is relied upon to formulate some actual policy decisions but not others, as well as understanding at what stage in the policy process this assessment actually takes place.

Some of the evidence to date should provide pause for those who believe that CBA is always used, is always done well and is always influential in policy formulation. Yet the finding that 'real world' decisions routinely downplay CBA also needs to be interpreted with care and could well be a matter of degree across different policy venues. For example, CBA is only one input to the decision in many (or most) cases. There are other complementary decision making procedures, as we have discussed, which vie for consideration and will help shape policy outputs and outcomes.

Nevertheless, there is growing recognition of the political motives that could explain both the use and influence (or otherwise) of CBA on policy decisions (Hahn and Tetlock 2008). Some of these considerations are factors which might have a bearing on how any form of evidence informs decisions: for example using formal evidence simply to justify decisions which, for all intents and purposes, already have been made. Yet, it could be that CBA is relatively more prone to these political machinations. All of this is clearly important to placing policy appraisal, including CBA, within a realistic understanding of how the policy formulation process actually works. Critically, however, it does not change the fundamental role of CBA. This remains the crucial task of explaining how a policy should look if an economic approach is considered to be consequential to that judgement. Indeed, if decision makers are genuinely interested in this policy formulation tool then what is known about actual use and influence of CBA should also be translated into practical implications for enhancing its role.

For example, while official CBA guidelines are no guarantee of actual use, these remain focal publications, setting the bar for how appraisal should be done. It is important that these guidelines reflect, in a practical way, the frontier of knowledge. Translating them into action, however, requires an additional range of considerations. Some of this may involve increasing the economic literacy needed to undertake good quality appraisals (Pearce et al. 2006), particularly in those policy venues with relatively little experience in this respect. 
Political considerations may also raise the risk of biased appraisals and put a premium on understanding better the institutional process for undertaking CBA. This involves asking questions not only about how CBA is undertaken but also by whom, how and in what policy venue it is organized (Florio and Sartori 2010; IEG 2011). The starting point for this might be the insight that responsibility for conducting CBA should not be assigned solely to those with a critical stake in a project's implementation (IEG 2011). In the case of EU Regional Policy, this has involved expanding the role for ex post cost-benefit assessment as a way of creating incentives for good studies to be done ex ante by member states applying for regional funds. Other proposals involve a separation of responsibilities for conducting ex ante studies in terms of 'who' is doing the analysis. In this way, those appraising a proposal are placed at arm's length from the project or policy (perhaps based in a central agency) rather than the analysis being done by beneficiaries of the proposed action.

Of course, no policy system is likely to be perfect in all these respects and each will be associated too with different political considerations. For example, there may be little appetite amongst politicians for adding costly ex post studies to look at decisions which are literally history and a potential source of political embarrassment (Hahn and Tetlock 2008; see also Chapter 8, this volume). A central agency for conducting ex ante assessment may need to rely on information from parties that the separation was designed to keep at greater distance from the analysis. Nonetheless, consideration of these and other policy capacity-related challenges (see Chapters 8 and 9, this volume) is crucial if policy formulators are serious about addressing the gap between the imagined and actual use and influence of CBA in the 'real world'.

\section{NOTES}

1. This chapter draws on and updates Pearce et al. (2006) and Atkinson and Mourato (2008).

2. The Kaldor-Hicks 'compensation principle' establishes this more formally, through the idea of hypothetical compensation as a rule for deciding on policies and projects in reallife contexts (Hicks 1939; 1943; Kaldor 1939). What this amounts to is the recognition that projects and policies entail (almost inevitably) losses to some groups and individuals as well as gains to others. This alone is not a reason, according to this tradition, to reject proposed actions. So long as actions create gains which are greater than the losses, there is scope for gainers potentially to compensate losers (and still be better off).

3. There are many comprehensive reviews of economic valuation methods more generally (for example, Bateman et al. 2002; Champ et al. 2003; Freeman 2003; Pearce et al. 2006; Hanley and Barbier 2009).

4. The CBA approach to decision making is based on 'individual values' in the sense of adding up how individuals value a proposed policy change. For some this is in conflict 
with notions of 'shared values' (see, for example, Fish et al. 2011). This has roots in earlier discussions about how people value changes, in the context of environmental policy, as consumers or citizens (Sagoff 1988). The current emphasis on shared values considers the way in which the environment has collective meaning and significance for communities of people and how the appraisal process might ignore this insight. How these shared values might be more formally incorporated in policy appraisal remains work-in-progress.

\section{REFERENCES}

Alberini, A. and J. Kahn (eds) (2006), Handbook on Contingent Valuation, Cheltenham, UK and Northampton, MA, USA: Edward Elgar Publishing.

Atkinson, G. and S. Mourato (2008), 'Environmental cost-benefit analysis', Annual Review of Environment and Resources, 33, 317-343.

Atkinson, G., S. Mourato, S. Szymanski and E. Ozdemiroglu (2008), 'Are we willing to pay enough to "back the bid"? Valuing the intangible impacts of hosting the Summer Olympic Games', Urban Studies, 45 (2), 419-444.

Bateman, I.J., D. Burgess, W.G. Hutchinson and D.I. Matthews (2008), 'Contrasting NOAA Guidelines with learning design contingent valuation (LDCV): preference learning versus coherent arbitrariness', Journal of Environmental Economics and Management, 55, 127-141.

Bateman, I.J., B. Fisher, E. Fitzherbert, D. Glew and R. Naidoo (2010), 'Tigers, markets and palm oil, market potential for conservation', Oryx, 44 (2), 230-234.

Bateman, I.J., R.T. Carson, B. Day et al. (2002), Economic Valuation with Stated Preference Techniques, Cheltenham, UK and Northampton, MA, USA: Edward Elgar Publishing.

Beckerman, W. and C. Hepburn (2007), 'Ethics of the discount rate in the Stern Review on the economics of climate change', World Economics, 8, 187-210.

Belli, P., J. Anderson, H. Barnum, J. Dixon and J-P. Tan (1998), Handbook on Economic Analysis of Investment Operations, Washington, DC: The World Bank.

Blake, A. (2005), The Economic Impact of the London 2012 Olympics, Christel De Haan Tourism and Travel Research Institute, Nottingham University Business School.

Boardman, A.E., D.H. Greenberg, A.R. Vining and D.L. Weimer (2011), CostBenefit Analysis, Concepts and Practice, 4th edition, New Jersey: Prentice-Hall.

Champ, P.A., K.J. Boyle and T.C. Brown (eds) (2003), A Primer on Nonmarket Valuation, Dordrecht: Kluwer Academic Publishers.

COWI (2011), Ex post Evaluation of Cohesion Policy Interventions 2000-2006 Financed by the Cohesion Fund (including former ISPA) Work Package C Cost Benefit Analysis of Environment Projects. Final report, Brussels: European Commission Directorate-General Regional Policy.

de Rus, G. (2011), Introduction to Cost-Benefit Analysis: Looking for Reasonable Shortcuts, Cheltenham, UK and Northampton, MA, USA: Edward Elgar Publishing.

de Rus, G. and C.A. Nash (2007), In what Circumstances is Investment in HSR Worthwhile?, Institute for Transport Studies, University of Leeds.

Defra (Department for Environment, Food and Rural Affairs) (2007), The Air 
Quality Strategy for England, Scotland, Wales and Northern Ireland, Volume 2, London: Defra.

Dubourg, W.R. and J. Hamed (2005), The Economic and Social Costs of Crime Against Individuals and Households 2003/04, London: Home Office.

Dunn, H. (2012), Accounting for Environmental Impacts, Supplementary Green Book Guidance, London: HM Treasury/Defra.

European Commission (2008), Guide to Cost-Benefit Analysis of Investment Projects, Brussels: European Commission Directorate General Regional Policy.

Fish, R., J. Burgess, A. Church and K. Turner (2011), 'Shared values for the contributions ecosystem services make to human well-being', in NEA (National Ecosystem Assessment), The UK National Ecosystem Assessment Technical Report, Cambridge: UNEP-WCMC, pp. 1183-1193.

Florio, M. and D. Sartori (2010), Getting Incentives Right: Do We Need Ex Post $C B A$ ?, Milan: Working Paper No. 01/2010, Centre for Industrial Studies.

Flyvbjerg, B., M.K. Skamris Holm and S.L. Buhl (2003), 'How common and how large are cost overruns in transport infrastructure projects?', Transport Reviews, $23(1), 71-88$.

Freeman, A.M. III (2003), The Measurement of Environmental and Resource Values, Washington, DC: Resources for the Future.

Gowdy, J. (2004), 'The revolution in welfare economics and its implications for environmental valuation and policy', Land Economics, 80, 239-257.

Hahn, R.W. and P.M. Dudley (2007), 'How well does the US Government do benefit-cost analysis?', Review of Environmental Economics and Policy, 1(2), 192-211.

Hahn, R.W. and R.C. Tetlock (2008), 'Has economic analysis improved regulatory decisions?', Journal of Economic Perspectives, 22 (1), 67-84.

Hanley, N. and E.B. Barbier (2009), Pricing Nature, Cost-Benefit Analysis and Environmental Policy, Cheltenham, UK and Northampton, MA, USA: Edward Elgar Publishing.

Hicks, J.R. (1939), 'Foundations of welfare economics', Economic Journal, 49, 696-712.

Hicks, J.R. (1943), 'The four consumer's surpluses', Review of Economic Studies, 11, 31-41.

HM Treasury (2003), The Green Book, Appraisal and Evaluation in Central Government, London: HM Treasury.

IEG (Independent Evaluation Group) (2011), Cost-Benefit Analysis in World Bank Projects, Washington, DC: World Bank.

IPCC (Intergovernmental Panel on Climate Change) (1996), Climate Change 1995, Economic and Social Dimensions of Climate Change, Cambridge: Cambridge University Press.

Kaldor, N. (1939), 'Welfare propositions of economics and interpersonal comparisons of utility', Economic Journal, 49, 549-552.

Kelman, S. (2005), 'Cost-benefit analysis: an ethical critique (with replies)', in R.N. Stavins (ed.), Economics of the Environment: Selected Readings, 5th edition, New York: W.W. Norton \& Company, pp. 260-275.

Little, I. and J. Mirrlees (1994), 'The costs and benefits of analysis, project appraisal and planning twenty years on', in R. Layard and S. Glaister (eds), Cost-Benefit Analysis, 2nd edition, Cambridge: Cambridge University Press, pp. 199-234. 
Londero, E.H. (2003), Shadow Prices for Project Appraisal, Theory and Practice, Cheltenham, UK and Northampton, MA, USA: Edward Elgar Publishing.

MacLeod, M., P. Ekins, R. Vanner and D. Moran (2009), Understanding the Costs of Environmental Regulation in Europe, Cheltenham, UK and Northampton, MA, USA: Edward Elgar Publishing.

Mourato, S., G. Atkinson, J. Newcombe and E. Ozdemiroglu (2005), 'Cost-benefit test or statutory duty? The case of options to clean-up the River Thames', Water International, 30 (2), 174-183.

NEA (National Ecosystem Assessment) (2011), National Ecosystem Assessment Technical Report, UK National Ecosystem Assessment, UNEP-WCMC, Cambridge.

Newbery, D. (2006), 'Discussion', Economic Policy, April, 305-307.

OECD (2004), Regulatory Impact Analysis (RIA), Inventory, Paris: Organisation for Economic Co-operation and Development (OECD).

Pearce, D.W. (1998), 'Cost-benefit analysis and environmental policy', Oxford Review of Economic Policy, 14 (4), 84-100.

Pearce, D.W., G. Atkinson and S. Mourato (2006), Cost-Benefit Analysis and the Environment, Recent Developments, Paris: Organisation for Economic Cooperation and Development (OECD).

Persky, J. (2001), 'Cost-benefit analysis and the classical creed', Journal of Economic Perspectives, 15 (4), 199-210.

Randall, A. (2002), 'Taking benefits and costs seriously', in H. Folme and T. Tietenberg (eds), The International Yearbook of Environmental and Resource Economics, Cheltenham, UK and Northampton, MA, USA: Edward Elgar Publishing, pp. 250-272.

Randall, A. (2007), 'Benefit Cost Analysis and a Safe Minimum Standard', in G. Atkinson, S. Dietz and E. Neumayer (eds), Handbook of Sustainable Development, Cheltenham, UK and Northampton, MA, USA: Edward Elgar Publishing, pp. 91-105.

Sagoff, M. (1988), The Economy of the Earth, Cambridge: Cambridge University Press.

Santos, G. and G. Fraser (2006), 'Road pricing, lessons from London', Economic Policy, April, 263-310.

Stern, N. (2007), The Economics of Climate Change - The Stern Review, Cambridge: Cambridge University Press.

Stokey, E. and R. Zeckhauser (1978), A Primer for Policy Analysis, New York: W.W. Norton \& Company.

Turner, R.K. (2007), 'Limits to CBA in UK and European environmental policy: retrospects and future prospects', Environmental and Resource Economics, 37 (1), 253-269.

US EPA/US Environmental Protection Agency (2000), Guidelines for Preparing Economic Analyses, Washington, DC: US EPA.

Weitzman, M. (2007), 'A review of the Stern Review on the Economics of Climate Change', Journal of Economic Literature, 45, 703-724. 